\title{
Effects of Hydro-Climatic Fluctuations on Catchability of Fish in Vavuniya Reservoir, Sri Lanka
}

\author{
A.E.S. Patrick ${ }^{*}$, S. Kuganathan ${ }^{1}$ and U. Edirisinghe ${ }^{2}$ \\ Postgraduate Institute of Agriculture \\ University of Peradeniya \\ Sri Lanka
}

\begin{abstract}
Catch assessment and frame survey were performed to estimate the species wise and total catch in the Vavuniya reservoir along with hydro-climatic factors. Relationship between the hydro-climatic factors and species wise catch statistics were determined from calendar year, rainfall $(R F)$ and water level (WL) based quarters of the annum. Irregularity in the rainfall pattern shifted the heavy rainfall based quarter from October-December to February-April in 2013. Significant variation $(P<0.05)$ in the species composition of the catch in all the quarters, indicates the non-uniformity of the catch distribution. The WL showed a negative correlation and significant $(P<0.05)$ relationship between catchability. However, the correlation between WL and catch per unit effort (CPUE) with respect to gear ( $\mathrm{kg} /$ gear/day) was insignificant $(P>0.05, r=-0.327)$ However, there was a strong negative correlation between monthly average WL and CPUE in terms of $\mathrm{kg} /$ fisher/day. There were 5 exotic, 13 indigenous and 1 endemic (Esomus thermoicos) species identified. Oreochromis niloticus contributed 79\%, Cirrhinus mrigala (8.6\%) and Channa striata (7.6\%) of the catch. Data obtained from this study may be used as a baseline for the sustainable management and to achieve optimal catch.
\end{abstract}

Keywords: Catchability of fish, hydro-climatic fluctuation, species composition, Vavuniya reservoir

\section{INTRODUCTION}

Vavuniya reservoir is a medium perennial reservoir which has a surface area of 806 ha at full supply level with a maximum depth of $3.96 \mathrm{~m}$. Primary water source of vavuniya reservoir, which is situated in the dry zone (Northern Province) is monsoonal and convection rains. Both catch and productivity of a reservoir is influenced by seasonal variations in hydroclimatic factors (Moses et al., 2002; Potts, 2003). Climate change has both direct and indirect impacts on fish stocks that are exploited commercially. Direct effects through reduced rainfall and greater evaporation and indirect effects, such as using more water for irrigation to balance reduced rainfall, could influence the overall water content of an inland reservoir (Brander, 2007). Climate change and consequent alteration in the seasonal hydro-climatic variation caused complete dry-out of Vavuniya reservoir from June to September 2012 due to draining of even dead storage for agriculture. Irregular rainfall pattern shifted the heavy rainfall based quarter from October-December to February-April quarter in 2013. During the last decade the rainfall based quarter was found in the October-December and November-

Department of Fisheries, Faculty of Science, University of Jaffna

Department of Animal Science, Faculty of Agriculture, University of Peradeniya, Sri Lanka

*. Corresponding author: patrickaes28@gmail.com 
January quarters only (Statistical Handbook of Vavuniya District, 2003-2013). Effects of seasonal hydro-climatic irregularities on fishing practices, management strategies and fish biology remain highly disputed in Vavuniya reservoir. The present study was designed to reveal the role of hydro-climatic changes on the catch ability of fish (total and species vise) in Vavuniya reservoir, with the view of increasing the fish catch at optimum sustainable level.

\section{METHODOLOGY}

Catch assessment survey, frame survey and logbook method were used to estimate the quantity (weight in $\mathrm{kg}$ ) of species-wise and total fish catch, along with hydro-climatic factors. Number of fishers, boats (canoes), fishing gear and relevant fisheries data were also collected to determine the catch and effort statistics. Census method was used for gathering information from the 17 fishers including 14 full-time fishers. Additionally, fish samples were randomly collected from the landing site and brought to the Environmental BioLaboratory of the Vavuniya Campus for species identification by using external morphology (Munro, 1955; Pethiyagoda, 1991) and other biological data.

Monthly total rainfall (RF) data were obtained from the Irrigation Department and monthly mean water level (WL) was calculated by using weekly data. The relationship among the hydro-climatic factors such as RF and WL and species wise and total catch statistics were determined from January to December 2013. Catch statistics were also calculated specieswise with respect to calendar year based four quarters (three-month intervals). Further, both $\mathrm{RF}$ and WL based quarters were determined by reckoning moving averages of monthly RF and WL patterns in order to obtain heavy, medium, low and very low quarters (Dematawewa et al, 2008). Chi-squrare Goodness-of-Fit test was performed for each species separately to determine the uniformity of catch distribution among the quarters. Linear regression and correlation analyses were done to find the Pearson correlation coefficient and statistical significance for continuous variables such as hydro-climatic factors, CPUE (kg/fisher/day/gear) and other catchability variables such as total catch, fishing days/fisher/month, total number of boat days/month and total number of gillnet days/month. All numerical data were analyzed by using Minitab 16.0 statistical software.

\section{RESULTS AND DISCUSSION}

Relationships between the monthly catch ability variables and the hydro-climatic factors were summarized statistically in Table 1 . Pearson correlation coefficient (r) between monthly total catch and WL showed significantly stronger negative correlation. Increase in WL, significantly reduced the number of fishing days/fisher/month, total number of boat days/month and total number of gillnet days/month in 2013. These results showed negative Pearson correlation coefficient values and indicated the strong inverse relationship between WL and catch ability. There was a strong negative correlation between monthly average WL and CPUE (kg/fisher/day). However, there was a weak negative correlation and insignificant relationship between WL and CPUE when reckoning kg/gear/day (Table 1). Rainfall increment also negatively correlated to the total catch, CPUE, fishing days/fisher/month, total number of boat days/month and total number of gillnet days/month. Number of boats (fiber glass canoe) used per time period was equal to number of fishers; a single boat was used by each fisherman. Inflated lorry tube; a modified fishing method was also used for harvesting in newly inundated areas during spilling. 
Table 1. Statistical summary of catch ability variables with hydro-climatic factors

\begin{tabular}{lcccc}
\hline \multirow{2}{*}{ Variables } & \multicolumn{4}{c}{ Hydro-climatic factors } \\
\cline { 2 - 5 } & \multicolumn{2}{c}{ Rainfall (RF) } & \multicolumn{2}{c}{ Water level (WL) } \\
\cline { 2 - 5 } & p-value & $\mathbf{r}$ & p-value & $\mathrm{r}$ \\
\hline Total catch & 0.381 & -0.278 & 0.020 & -0.658 \\
CPUE (kg/gear/day) & 0.750 & -0.100 & 0.290 & -0.327 \\
CPUE (kg/fisher/day) & 0.200 & -0.394 & 0.009 & -0.713 \\
No. of fishing days/fisher & 0.150 & -0.430 & 0.010 & -0.670 \\
No. of boat days & 0.159 & -0.430 & 0.020 & -0.637 \\
No. of gillnet days & 0.084 & -0.518 & 0.004 & -0.750 \\
\hline
\end{tabular}

There were 5 exotic, 13 indigenous and 1 endemic (Esomus thermoicos) species in the catch. Annual total fish production in 2013 in the Vavuniya reservoir was around 16,130 kg. Majority of the total catch (79\%) was Oreochromis niloticus followed by Cirrhinus mrigala $(8.6 \%)$. Among the indigenous species Channa striata was the dominant species which was the third highest in the catch ( $7.6 \%$ of the total catch) (Table 2$)$.

Table 2. Species vise monthly fish catch $(\mathrm{kg})$ of Vavuniya reservoir

\begin{tabular}{|c|c|c|c|c|c|c|c|c|}
\hline \multirow{2}{*}{ Month } & $\begin{array}{c}O . \\
\text { niloticus }\end{array}$ & $\begin{array}{c}C . \\
\text { striata }\end{array}$ & $\begin{array}{c}C . \\
\text { mrigala }\end{array}$ & $\begin{array}{c}\text { Puntius } \\
\text { sp. }\end{array}$ & $\begin{array}{c}\text { L. } \\
\text { rohita }\end{array}$ & $\begin{array}{c}\text { L. } \\
\text { dussumieri }\end{array}$ & Others* & \multirow{2}{*}{ Total } \\
\hline & {$[\mathrm{E}]$} & {$[\mathrm{I}]$} & {$[\mathrm{E}]$} & [I] & {$[\mathrm{E}]$} & {$[\mathrm{I}]$} & {$[\mathrm{I}] \&[\mathrm{E}]$} & \\
\hline Jan & 437 & 14 & 13 & 00 & 15 & 00 & 0.5 & 479 \\
\hline Feb & 343 & 27 & 37 & 01 & 03 & 00 & 0.0 & 411 \\
\hline Mar & 394 & 57 & 66 & 02 & 00 & 00 & 0.0 & 519 \\
\hline Apr & 620 & 49 & 36 & 02 & 00 & 00 & 0.0 & 707 \\
\hline May & 578 & 144 & 231 & 00 & 00 & 00 & 0.0 & 953 \\
\hline Jun & 1,976 & 123 & 264 & 27 & 00 & 03 & 0.0 & 2,393 \\
\hline Jul & 688 & 287 & 296 & 33 & 12 & 00 & 15.0 & 1,331 \\
\hline Aug & 1,318 & 189 & 148 & 240 & 49 & 07 & 2.0 & 1,953 \\
\hline Sep & 982 & 104 & 72 & 28 & 86 & 05 & 0.0 & 1,277 \\
\hline Oct & 2,030 & 119 & 121 & 36 & 57 & 10 & 1.0 & 2,374 \\
\hline Nov & 2,129 & 93 & 105 & 08 & 91 & 10 & 2.0 & 2,438 \\
\hline Dec & 1,202 & 27 & 0 & 29 & 22 & 11 & 4.0 & 1,295 \\
\hline Total & 12,696 & 1,233 & 1,389 & 406 & 335 & 46 & 24.5 & 16,130 \\
\hline$\%$ & 79.0 & 7.6 & 8.6 & 2.5 & 1.9 & 0.25 & 0.15 & 100 \\
\hline
\end{tabular}

*Others include: Endemic; Esomus thermoicos, Indigenous [I]; Amblyphyrangodon mellatinus, Anabas testudineus, Anguilla nebulosa, Glossogobius giuris, Heteropneustes fossilis, Mystus keletius, Puntius dorsalis, Puntius fillamentosus, Systomus timbiri Wallaga attu and Macrobrachium rosenbergii, Exotic [E]; Catla catla, Cyprinus carpio and Trichogaster pectoralis in minimum quantities.

Categorization of calendar year based quarters and WL based quarters overlapped completely (Fig. 1). Calendar year based quarters, water level based quarters and rainfall based quarters (Fig. 2) in 2013 showed non-uniformity of catch distribution of each fish species and was found to be significant for each species $(\mathrm{P}<0.05)$ among the quarters. 


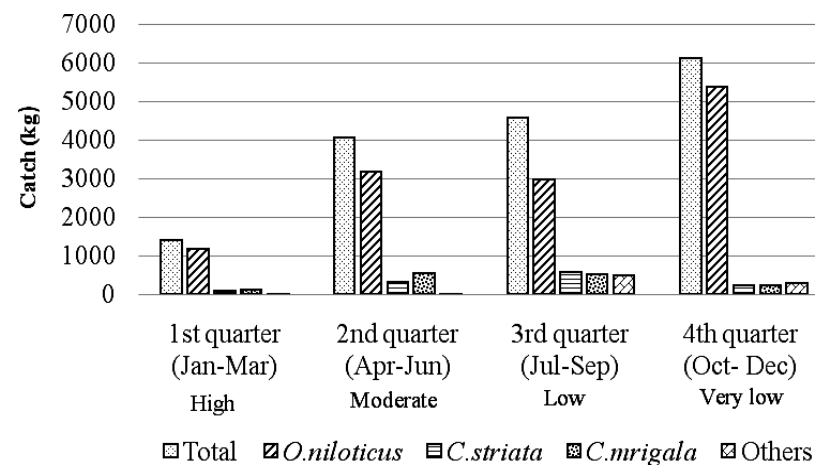

Fig. 1. Relationship of catch data (kg) with calendar year / WL based quarters

There was a steady increase in catch along the calendar year based and water level based quarters. Minimum catch was in the initial quarter (January - March) while the maximum was in the last quarter (October- December) (Fig. 1). Fish catch reached the maximum (4,676 - 5,604 kg) at low rainfall based quarters. The catch was lowest $(1,638 \mathrm{~kg})$ in the heavy rainfall based quarter (February- April), when compared with the other quarters (Fig. 2).

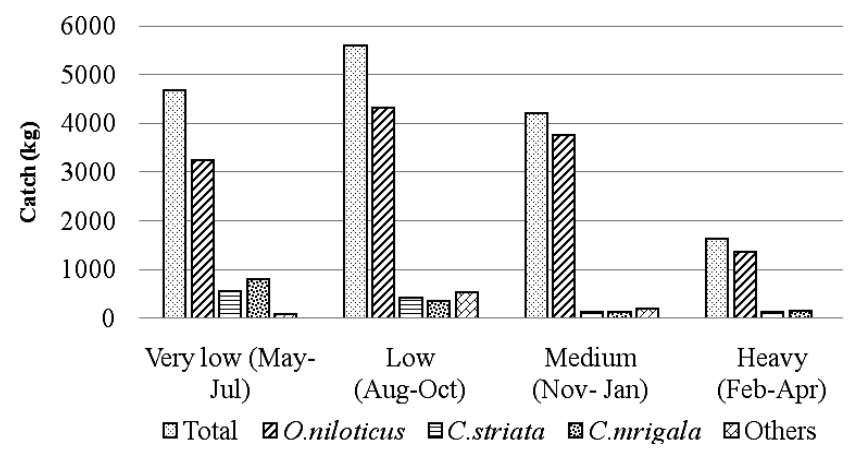

Fig. 2. Relationship of catch data $(\mathrm{kg})$ with rainfall based quarters

Although the water level depends on the rainfall, higher evaporation rate; seepage and mainly the draining for irrigation contribute to the water level fluctuations considerably. Hence, the rainfall regimes of the previous months also influence the hydro-dynamics of the reservoir rather than the rainfall of the respective month. Results showed insignificant relationship and less positive correlation $(r=0.231)$ between RF and WL values in 2013. Though, Vavuniya reservoir is a perennial reservoir according to classification (Edirisinghe, 2009), this was completely dried during June to September 2012. However, there was a significant quantity of water as well as different fish species were supplemented from Madukanda reservoir during subsequent rainy season. Madukanda reservoir (MSL $106.68 \mathrm{~m}$ ) is a deep minor-perennial and located $4 \mathrm{~km}$ away from Vavuniya reservoir (MSL $93.88 \mathrm{~m}$ ) and did not run dry like Vavuniya reservoir during the said drought period. Moving averages of monthly total rainfall in the Vavuniya District revealed that the heavy rainfall based quarter during the last couple of decades was found only in Oct-Dec and Nov-Jan quarters 
(Statistical Handbook of Vavuniya District, 2003 and 2013). Fingerling stocking and ceasing fishing activities during heavy rainfall based quarters have been a common management strategy in Vavuniya reservoir. Interestingly, the heavy rainfall based quarter was shifted to Feb-Apr quarter in 2013 due to irregular rainfall. This phenomenon favoured the irrational way of fingerling stocking and fishing activities directly and indirectly. Fishers continued fishing throughout the year (2013) without a break and did not allow fingerlings to attain a suitable harvesting size. Species composition and abundance of the fish in the reservoir depended on the stocking of fingerlings and natural recruitment. Oreochromis niloticus, Cirrhinus mrigala Labeo rohita and Catla catla were the major stocked exotic species. Natural recruitment and immigration were shown by both endemic (Esomus thermoicos) and indigenous species such as Puntius sp., Channa striata and Wallaga attu etc. (Table 2). There were 14 full time fishers out of the total 17 fishers, who used gill nets of $3 \frac{1}{2} 2$ ", 33/4", 4" and 41/2" (stretched mesh sizes) as major fishing gear with other illegal nets. However, in 2013 only $3 \frac{1}{2}$ " and 33/4" of gillnet types were used along with smaller sized monofilament nets. This practice led to catch undersized fish, which included the recently stocked fingerlings, naturally immigrated as well as fish entered due to recruitment. As a result of complete eradication of fish due to unprecedented drought in the previous year the annual fish catch in 2013 was very low $(16,130 \mathrm{~kg}$ ) compared to previous years (Statistical Handbook of Vavuniya District, 2013).

Table 3. Total annual catch data $(\mathrm{kg})$ of the Vavuniya reservoir

\begin{tabular}{rccccc}
\hline Year & 2008 & 2009 & 2010 & 2011 & 2012 \\
Catch & 36750 & 32290 & 35850 & 43435 & 65376 \\
\hline
\end{tabular}

Source: Statistical Handbook of Vavuniya District, 2003-2013.

Climate change and its direct effects through reduced rainfall and indirect effects via irrigation is predicted to have major impacts on fish production (Brander, 2007), potentially influencing the economy of many developing nations globally (Allison et al., 2009). When the relationship between hydro-climatic variability and fish catch abilty were analyzed statistically by using linear regression, correlation analysis and non-uniformity of the catch distribution of the year 2013 in Vavuniya reservoir, results revealed that when the hydroclimatic factors (RF and WL) increased, the monthly catch ability variables decreased. Welcomme (2001) and Moses et al. (2002) also indicated that the hydro-climatic factors such as rainfall and water level in the reservoir affect the catch per unit effort as well as effort of fishers. Lower overall CPUE values in 2013 were due to the prevailed drought in 2012. Although ten nets per fisher have been fixed by the Fisheries Society, more than 10 nets were used by majority of fishers, which led to lesser CPUE (kg/gear/day) value for gear than for fisher. Comparatively WL in the Vavuniya reservoir showed a strong negative correlation with catch ability than RF (Table 1). This was due to the significantly high contribution of Oreochromis sp. (79\%) to the monthly catch (Table 2), whose catchability depended mainly on WL rather than RF. These findings also supported by the similar observations in Sorabora reservoir (Dematawewa et al., 2008).

Categorization of the year into calendar year based quarters, water level based quarters and rainfall based quarters are useful in fisheries management. There was a unique distribution shown by each species among the quarters of each category and found to be significant. Higher catches of Cirrhinus mrigala and Channa striata were observed in the very low rainfall based quarter. This could be due to higher density of carps in the reservoir due to low water volume. $O$. niloticus dominated the total catch of each month mainly due to its natural 
breeding and habit of continuous movement for feeding. Among rainfall based quarters, the total catch increased with decreasing rainfall. Lower rainfall based quarter (Aug-Oct) received comparatively higher fish catch than lowest rainfall based quarter (May-Jul) (Fig. 2). These data reveal that importance of the water level than rainfall in Vavuniya reservoir. However, when water level increased up to FSL (Fully Supply Level) total catch decreased significantly mainly due to fish movement to the productive littoral zone in addition to other natural causes. This is the reason for some fishers to use lorry tubes to place the gill nets in the peripheral areas of the reservoir. Dematawewa et al. (2008) also found that the higher catch statistics were observed in the dry season due to increase in water temperature and decrease in water level, which resulted in more active and aggregation of fish in a limited area, and more fishers involved in fishing. In Vavuniya reservoir, during the period of low water level, fishers caught fish even during the day time, which resulted in significantly higher catch. Therefore, fishing effort in Vavuniya reservoir also increased with the decreasing water level and resulted in higher catch. Hence, changes in hydro-climatic fluctuations influenced the catch ability in the Vavuniya reservoir both directly and indirectly.

\section{CONCLUSIONS}

Water level in the Vavuniya reservoir showed a strong influence on catch ability variables than rainfall. Monthly total catch was dominated by $O$. niloticus and the catch of other species was mainly depended on water level. Categorization of rainfall based, water level based and calendar year based quarters with respect to its catch statistics are useful in efficient aquatic resource management, since they are specific to the particular reservoir. Hence the data obtained from this study could serve as a baseline to optimize the fish catch in the Vavuniya reservoir at sustainable levels.

\section{REFERENCES}

Allison, E.H., Perry, A.L., Badjeck, M.C., Adger, W.N., Brown, K., Conway, D., Halls, A.S., Pilling, G.M., Reynolds, J.D., Andrew, N.L. and Dulvy, N.K. (2009). Vulnerability of national economies to the impacts of climate change on fisheries. Fish, 10, $173-196$.

Brander, K.M. (2007). Global fish production and climate change. P. Natl. Acad. Sci. Biol., 104, 19709 - 19714.

Dematawewa, C.M.B., Wickremasinghe, E.S and Edirisinghe U. (2008). Some effects of seasonal hydro-climatic factors on catchability of fish in minor-perennial Sorabora reservoir, Sri Lanka. Sri Lanka Journal of Animal Production., 9, 39 - 53.

Edirisinghe, U. (2009). Freshwater capture fisheries and aquaculture of Sri Lanka. ISBN 978-955-52124-0-3, Anura Printers, Kurunegala, Sri Lanka.

Moses, B.S., Udoidiong, O.M. and Okaon, A.O. (2002). A statistical survey of the artisanal fisheries of south-eastern Nigeria and the influence of hydro climatic factors on catch and resource productivity. Fisheries Research, 57(3), 267 - 278. 
Munro, I.S.R. (1955). The marine and freshwater fishes of Ceylon. Department of External Affairs, Canberra, Australia.

Pethiyagoda, R. (1991). Freshwater fishes of Sri Lanka. Wildlife Heritage Trust, Colombo.

Potts, W.M. (2003). Towards the Development of Species-Specific Fish Productin Models for Small Reservoirs in Southern Africa. Unpublished PhD Thesis. Dept. of Ichthyology and Fisheries Science, Rhodes University, South Africa. [On line]. [Accessed on 10.01.2014] Available at http://eprints.ru.ac.za/83/01/Potts_PhD.pdf>

Statistical Handbook of Vavuniya District. (2003). District Planning Secretariat, District Secretariat, Vavuniya, Sri Lanka.

Statistical Handbook of Vavuniya District. (2013). District Planning Secretariat, District Secretariat, Vavuniya, Sri Lanka.

Welcomme, R.L. (2001). Inland fisheries: Ecology and Management. Fishing News Books. Blackwell Science, Oxford. 